\title{
GLIFOSATO E MANGANÊS NA CONCENTRAÇÃO DE NUTRIENTES FOLIAR E CARACTERÍSTICAS AGRONÔMICAS DA SOJA
}

\author{
Alexandre Perozini ${ }^{1}$, Edson Lazarini ${ }^{2}$, Marcelo Carvalho Minhoto Teixeira Filho ${ }^{3}$, Fernando Shintate Galindo ${ }^{3}$ \\ ${ }^{1}$ Instituto Federal de Mato Grosso - IFMT, Campus São Vicente, São Vicente da Serra. Santo Antônio do Leverger-MT. \\ ${ }^{2}$ Universidade Estadual Paulista - UNESP, Departamento de Fitotecnica, Tecnologia de Alimentos e Sócio Economia, \\ Faculdade de Engenharia de Ilha Solteira, Ilha Solteira, SP. ${ }^{3}$ Universidade Estadual Paulista - UNESP, Departamento de \\ Fitossanidade, Engenharia Rural e Solos, Faculdade de Engenharia de llha Solteira, Ilha Solteira, SP. E-mail: \\ fs.galindo@yahoo.com.br
}

\section{RESUMO}

Objetivou-se estudar os efeitos da aplicação de glifosato e manganês ( $\mathrm{Mn}$ ) em estádios de desenvolvimento na nutrição e características agronômicas da cultura da soja, no município de Selvíria-MS, Brasil, na safra 2012/13, utilizando-se a variedade de soja BRS Valiosa RR em um Latossolo Vermelho Distrófico, de textura argilosa. O delineamento experimental foi em blocos casualizados com quatro repetições, distribuídos em esquema fatorial $6 \times 2$, sendo: seis doses de aplicação de glifosato (a- $0 \mathrm{~g}$ i.a. ha ${ }^{-1}$, b- aplicação de $720 \mathrm{~g}$ i.a. ha ${ }^{-1}$ no estádio V3, c- 1440 g i.a. ha ${ }^{-1}$ totalmente em V3, d- aplicação de $1440 \mathrm{~g}$ i.a. ha ${ }^{-1}$ parcelado em duas aplicações de 720+720 g i.a. ha ${ }^{-1}$ em V3 e V7, e - 1440 g i.a. ha ${ }^{-1}$ totalmente em V7, e f - aplicação de 2160 g i.a. ha ${ }^{-1}$ parcelado em duas aplicações de 720+1440 g i.a. ha ${ }^{-1}$ em V3 e V7; com ou sem aplicação de $\mathrm{Mn}\left(0 \mathrm{~g} \mathrm{ha} \mathrm{h}^{-1}\right.$ e $\left.350 \mathrm{~g} \mathrm{ha}{ }^{-1}\right)$, no estádio V5. A aplicação foliar de $\mathrm{Mn}$ e de glifosato não influenciou as concentrações dos macro e micronutrientes foliar da cultura da soja. $\mathrm{O}$ glifosato nas doses de $720+1440 \mathrm{~g}$ i.a. ha ${ }^{-1}$, aplicado nos estádios V3 e V7, associado a adubação foliar com $350 \mathrm{~g} \mathrm{ha}^{-1}$ de $\mathrm{Mn}$ no estádio V5, reduz a altura de inserção da primeira vagem, porém aumenta o número de grão por vagem. A produtividade de grãos de soja foi reduzida com a aplicação de glifosato na dose de 720+1440 g i.a. $\mathrm{ha}^{-1}$, nos estádios V3 e V7, independentemente da aplicação foliar com Mn.

Palavras-chave: Glycine $\max$ (L.) Merril; Produtividade; N-(fosfonometil) Glicina; adubação foliar; micronutriente.

\section{GLYPHOSATE AND MANGANESE AFFECTING FOLIAR NUTRIENT CONCENTRATION AND AGRONOMIC CHARACTERISTICS OF SOYBEAN}

\begin{abstract}
The objective of this study was to evaluate the effects of glyphosate and manganese (Mn) application at developmental stages in the nutrition and agronomic characteristics of soybean crop, in the municipality of Selvíria-MS, Brazil, in the 2012/13 harvest, using the soybean variety BRS Valiosa RR in an Oxisol, with a clayey texture. The experimental design was a randomized block with four replications in a $6 \times 2$ factorial scheme, being: Six glyphosate application rates $\left(0 \mathrm{~g}\right.$ a.i. $\mathrm{ha}^{-1}$, application of $720 \mathrm{~g}$ a.i. ha ${ }^{-1}$ in V3 stage, $1440 \mathrm{~g}$ a.i. ha ${ }^{-1} \mathrm{~V} 3$, $720+720 \mathrm{~g}$ a.i. ha ${ }^{-1}$ V3 and V7, $1440 \mathrm{~g}$ a.i. ha ${ }^{-1}$ in V7, and application of $720+1440 \mathrm{~g}$ a.i. ha ${ }^{-1}$ V3 and V7; with or without $\mathrm{Mn}$ application ( $0 \mathrm{~g} \mathrm{ha}^{-1}$ and $350 \mathrm{~g} \mathrm{ha}^{-1}$ ) in $\mathrm{V} 5$ stage. Foliar applications of $\mathrm{Mn}$ and glyphosate did not influenced the leaf concentrations of macro and micronutrients in soybean. Glyphosate at doses of 720+1440 g a.i. ha ${ }^{-1}$, applied in stages V3 and V7, associated with foliar fertilization with $350 \mathrm{~g} \mathrm{ha}^{-1} \mathrm{Mn}$ in the V5 stage, reduces the first pod height, but increases the number grain per pod. Soybean yield was reduced with glyphosate application at a dose of 720+1440 $\mathrm{g}$ ai ha ${ }^{-1}$ in V3 and V7 stages, regardless of Mn leaf application. Keywords: Glycine $\max$ (L.) Merril; Yield. N-(phosphonomethyl) Glycine; foliar fertilization; micronutrient.
\end{abstract}

\section{INTRODUÇÃO}


Entre as safras de 2012/13 e 2014/15, a cultura da soja ocupou uma área média de 29,43 milhões de hectares, com produtividade média de $3.001 \mathrm{~kg} \mathrm{ha}^{-1}$, sendo grande parte da soja produzida no Brasil de origem transgênica, caracterizando-se como a principal cultura agrícola anual em área semeada, e em valor de comercialização (CONAB, 2015). O grão de soja é a principal fonte de proteína vegetal, essencial componente de produção na alimentação animal, além da crescente utilização na alimentação humana (IGNÁCIO et al., 2015). Entretanto, para obtenção de elevadas produtividades, observa-se a necessidade da utilização de novas tecnologias, como a transgenia, porém, sua utilização errônea pode provocar impactos ainda pouco divulgados (GONÇALVES et al., 2014).

O glifosato é um potente herbicida de pósemergência, largo espectro e não seletivo (YAMADA; CASTRO, 2007). Na soja Roundup Ready (RR), é aplicado em pós-emergência durante a fase vegetativa da cultura, absorvido e translocado nas plantas, promovendo eficiente controle das plantas daninhas em um estádio em que essa competição seria extremamente prejudicial à cultura comercial.

Embora seja eficiente no controle de plantas daninhas, existem relatos por parte de alguns pesquisadores dos diferentes efeitos fisiológicos induzidos por esse herbicida. A soja tolerante ao glifosato pode sofrer injúrias ocasionadas pelo herbicida, sob determinadas condições e formulações do sal do produto (BASSO et al., 2011). Além disso, observações no campo realizadas por pesquisadores nos Estados Unidos identificaram um amarelecimento das folhas na soja RR após a aplicação de glifosato (HUBER, 2007). Foi sugerido que a aplicação desse herbicida era responsável pelo amarelecimento, causado por uma deficiência induzida de micronutriente, especialmente o Mn (CORREIA; DURIGAN, 2009; FENNER et al., 2012). Tal fato serviu de alerta aos produtores e pesquisadores, pois poderia ocasionar uma diminuição da produtividade de grãos na cultura. Ademais, o cultivo de variedades de soja RR altamente produtivas, na região dos Cerrados em solos ácidos e, de baixa fertilidade natural, só foi possível mediante a correção deste solo com calcário, fato que, também induz a deficiência de $\mathrm{Mn}$, podendo agravar ainda mais as injurias ocasionadas pelo glifosato na absorção deste nutriente (STEFANELLO et al., 2011).

O manganês $(\mathrm{Mn})$ é um elemento essencial na nutrição de plantas e desempenha importantes funções, entre elas, a participação na fotossíntese, no metabolismo do nitrogênio, bem como, precursor de aminoácidos aromáticos, hormonais (auxinas), fenóis e ligninas (CARVALHO et al., 2015). Entretanto, a função mais bem definida do manganês é a da reação fotossintética, onde ocorre a quebra fotoquímica da molécula da água (reação de Hill), a qual gera 4 elétrons, os quais são utilizados fotossistema II (BASSO et al., 2011). Em condição de carência de Mn ocorre clorose entre as nervuras das folhas mais novas, as quais se tornam verde-pálido e passam para amarelo-pálido. Áreas necróticas marrons desenvolvem-se nas folhas à medida que a deficiência se torna mais severa.

Diversos autores relataram redução no acúmulo de nutrientes, alterações na nodulação e, respectivamente, na produção de clorofila e obtenção do N (JOHAL; HUBER, 2009; ZOBIOLE et al., 2010; SERRA et al., 2011; ZOBIOLE et al., 2011) em função da utilização do glifosato. Bott et al. (2008), verificaram que a aplicação de glifosato pode exercer efeito negativo no crescimento da planta e no estado nutricional, sugerindo uma inter-relação com fatores ambientais. Zobiole et al. (2010), concluíram que o estado nutricional da soja RR é afetado pelo glifosato e que as recomendações nutricionais para os cultivos RR devem considerar a eficiência nutricional reduzida imposta pela transgenia RR, bem como o impacto adicional do glifosato. Entretanto, Correia e Durigan (2009), constataram que o glifosato não prejudicou a absorção ou metabolismo do $\mathrm{Mn}$. De maneira semelhante, Rosolem et al. (2010), em condições controladas não encontraram evidências de efeitos negativos do glifosato na absorção, acúmulo e distribuição do $\mathrm{Mn}$ na soja $\mathrm{RR}$ e que a transgenia RR não influenciou na resposta da planta a este nutriente. Segundo Bianco et al. (2012), a disponibilidade dos nutrientes no meio influencia diretamente a taxa de absorção de nutrientes, que por sua vez afetará seu acúmulo, pois somente se observam elevados acúmulos de um dado nutriente, quando, antecipadamente, ocorre alta absorção deste. Portanto, fatores como a aplicação do glifosato podem interferir 
diretamente no acúmulo dos nutrientes em soja, mesmo nas cultivares transgênicas.

No entanto, de acordo com Zobiole et al. (2010), as injúrias ocasionadas pelo glifosato são variáveis em função da cultivar de soja, da dose e da formulação deste herbicida, e de fatores ambientais. Ainda, a significância desta sintomatologia para o metabolismo da planta e suas consequências para a produtividade de grãos da cultura são poucos estudados. Neste sentido, a diagnose nutricional associado a avaliação do desempenho agronômico pode esclarecer os efeitos da aplicação de diferentes concentrações de glifosato em soja transgênica. Desta forma, o objetivou-se avaliar os efeitos da aplicação de doses de glifosato e de $\mathrm{Mn}$ via foliar em diferentes estádios fenológicos da soja, na concentração de nutrientes foliar, características agronômicas e produtividade de grãos de soja RR.

\section{MATERIAL E MÉTODOS}

O experimento foi desenvolvido no ano agrícola de 2012/13 na Fazenda de Ensino, Pesquisa e Extensão da Faculdade de Engenharia UNESP, localizada no município de Selvíria-MS, Brasil, cujas coordenadas geográficas aproximadas são $51^{\circ} 22^{\prime}$ de Longitude Oeste e $20^{\circ} 22^{\prime}$ Sul, e altitude de $335 \mathrm{~m}$ acima do nível do mar. Na Figura 1 encontram-se os valores médios mensais de temperatura máxima, mínima e média do $\operatorname{ar}\left({ }^{\circ} \mathrm{C}\right)$, umidade relativa do ar (\%) e precipitação pluvial $(\mathrm{mm})$, nos meses de outubro à março de 2012, período de condução do experimento.

Figura 1. Valores mensais médios de umidade relativa (\%), temperaturas mínimas e máximas $\left({ }^{\circ} \mathrm{C}\right)$ e precipitação total $(\mathrm{mm})$, no período de condução dos experimentos 2012/13 na área experimental da Fazenda de Ensino, Pesquisa e Extensão. Selvíria - MS, 2012/13.

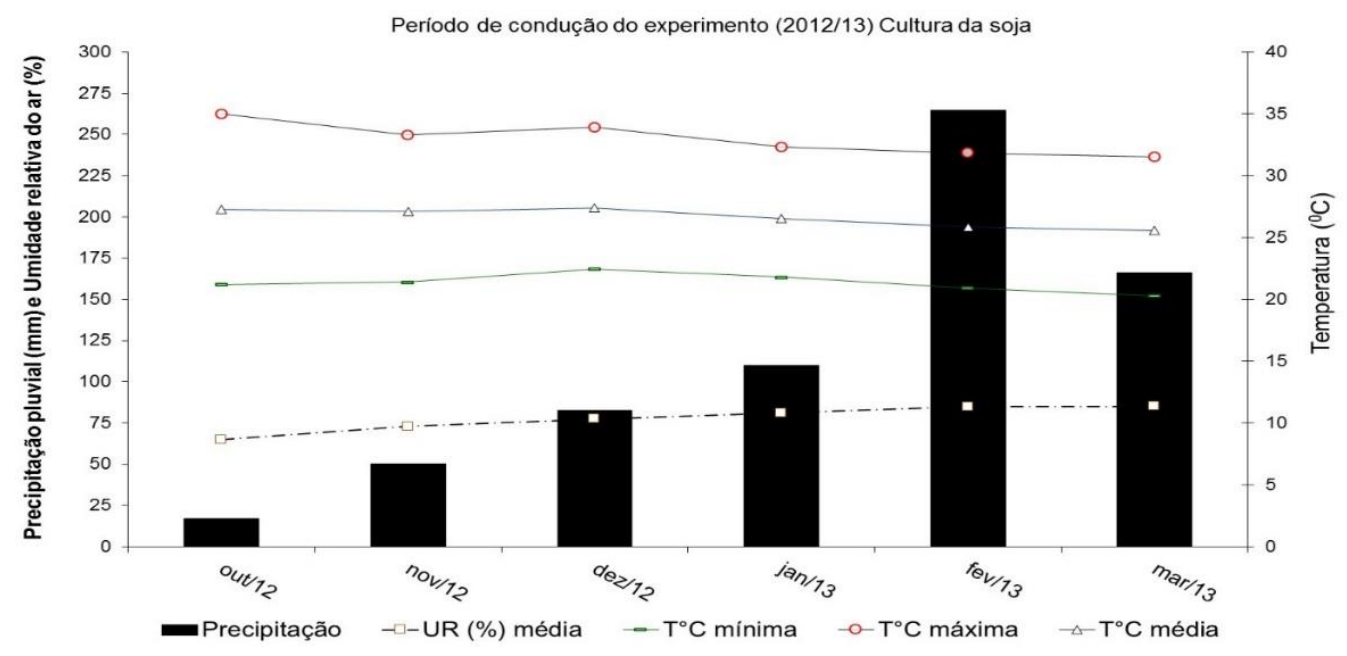

O solo da área foi classificado como Latossolo Vermelho Distrófico típico argiloso (Embrapa, 2013), com histórico de mais de 27 anos de ocupação por culturas anuais. Anteriormente à implantação do experimento, foi realizada a amostragem de solo na área experimental, na camada de 0 - 0,2 $\mathrm{m}$ para a caracterização química do solo, quanto aos valores de $\mathrm{pH}$, e teores de M.O. (P, K, Ca, Mg, S), H+Al (B, Cu, Fe, Mn e Zn). Resultado da análise de solo: $\mathrm{P}=26 \mathrm{mg} \mathrm{dm}^{-3} ; \mathrm{MO}=$ $23 \mathrm{~g} \mathrm{dm}^{-3} ; \mathrm{pH}\left(\mathrm{CaCl}_{2}\right)=5 ; \mathrm{K}=2,6 ; \mathrm{Ca}=21 ; \mathrm{Mg}=13$; $\mathrm{H}+\mathrm{Al}=34 \mathrm{mmol}_{\mathrm{c}} \mathrm{dm}^{-3}$ respectivamente; $\mathrm{Al}=1 ; \mathrm{S}$ $\mathrm{SO}_{4}=4 ; \mathrm{B}=0,25 ; \mathrm{Cu}=0,7 ; \mathrm{Fe}=20 ; \mathrm{Mn}=4,9 ; \mathrm{Zn}=$
$0,9 \mathrm{mg} \mathrm{dm}^{-3}$ respectivamente; $\mathrm{SB}=36,6 ; \mathrm{CTC}=70,6$; $\mathrm{V} \%=52$.

$\mathrm{Na}$ primeira quinzena de novembro de 2012, as plantas existentes na área experimental foram dessecadas com o uso do sal isopropilamina de $\mathrm{N}$-(phosphonomethyl) glicine na dose de $1440 \mathrm{~g}$ i.a. ha ${ }^{-1}$ (equivalente ácido) $\left(4,0 \mathrm{~L} \mathrm{ha}^{-1}\right.$ de glifosato) e então, sete dias após foi realizada a semeadura direta da soja (07/11/2012), utilizando-se a semeadora adubadora adequada para esta operação, em seguida fez-se a locação das parcelas experimentais.

No tratamento das sementes foi utilizado o produto a base de carboxim+thiram, na dose de 50 
+50 g i.a. por $100 \mathrm{~kg}$ de sementes, respectivamente. Nas sementes, ainda foi aplicado inoculante turfoso, objetivando-se atingir o mínimo de 600.000 células de Bradyrhizobium por semente, conforme recomendação Embrapa (2006). O espaçamento adotado foi de 0,45 metros entre linhas. A variedade de soja utilizada foi a BRS Valiosa RR, considerada de ciclo médio (maturação entre 123 a 130 dias) para a região e caracterizada por possuir hábito de crescimento determinado. Utilizou-se 16,2 sementes por metro de sulco, e a adubação de semeadura com $250 \mathrm{~kg} \mathrm{ha}^{-1} \mathrm{da}$ formulação 08-28-16, com base na análise de solo e em resultados de experimentos anteriores.

$O$ delineamento experimental foi em blocos casualizados com quatro repetições, distribuídos em esquema fatorial $6 \times 2$, sendo: seis doses de aplicação de glifosato (sem aplicação, $0 \mathrm{~g}$ i.a. ha ${ }^{-1}$, aplicação de $720 \mathrm{~g}$ i.a. ha ${ }^{-1}$ no estádio V3, 1440 g i.a. ha ${ }^{-1}$ em V3, $720+720$ g i.a. ha ${ }^{-1}$ em V3 e
V7, 1440 g i.a. ha ${ }^{-1}$ em V7, e aplicação de $720+1440$ g i.a. ha ${ }^{-1}$ em V3 e V7, com ou sem aplicação de $\mathrm{Mn}$ ( $0 \mathrm{~g} \mathrm{ha}^{-1}$ e $350 \mathrm{~g} \mathrm{ha}^{-1}$ ) no estádio V5, com as parcelas experimentais constituídas de seis linhas com dez metros de comprimento. Como área útil foi considerada as três linhas centrais, desprezando-se um metro em cada extremidade.

$\mathrm{Na}$ Tabela 1, constam os tratamentos do experimento. As pulverizações foliares foram realizadas sempre sem vento, com temperatura inferior a $30^{\circ} \mathrm{C}$ e umidade relativa do ar acima de $60 \%$, no período da manhã, com um pulverizador de barra de cinco metros de comprimento, provido com bicos leque 110-02, espaçados em cinquenta centímetros, acoplado ao trator, e calibrado para volume de aplicação de $200 \mathrm{~L} \mathrm{ha}^{-1}$ de calda. As aplicações do glifosato foram realizadas em 30/11 e 15/12, respectivamente nos estádios V3 e V7.

Tabela 1. Resumo dos tratamentos aplicados no experimento. Selvíria - MS, 2012/13

\begin{tabular}{|c|c|c|c|c|}
\hline Tratamentos & $\begin{array}{l}\text { glifosato (g i.a. ha }{ }^{-1} \text { ) } \\
\text { (equivalente ácido) e } \\
\text { estádio da soja }\end{array}$ & $\begin{array}{l}\text { Mn }\left(\mathrm{g} \mathrm{ha}^{-1}\right) \mathrm{e} \\
\text { estádio da soja }\end{array}$ & $\begin{array}{c}\text { Total glifosato } \\
\text { (g i.a. ha }{ }^{-1} \text { ) } \\
\text { (equivalente ácido) }\end{array}$ & $\begin{array}{c}\text { Total Mn } \\
\left(\mathrm{g} \mathrm{ha}^{-1}\right)\end{array}$ \\
\hline 1 & 0 & 0 & 0 & 0 \\
\hline 2 & 0 & 350 (V5) & 0 & 350 \\
\hline 3 & 720 (V3) & 0 & 720 & 0 \\
\hline 4 & 720 (V3) & 350 (V5) & 720 & 350 \\
\hline 5 & 1440 (V3) & 0 & 1440 & 0 \\
\hline 6 & 1440 (V3) & 350 (V5) & 1440 & 350 \\
\hline 7 & $720+720(V 3+V 7)$ & 0 & 1440 & 0 \\
\hline 8 & $720+720(V 3+V 7)$ & 350 (V5) & 1440 & 350 \\
\hline 9 & 1440 (V7) & 0 & 1440 & 0 \\
\hline 10 & 1440 (V7) & 350 (V5) & 1440 & 350 \\
\hline 11 & $720+1440(V 3+V 7)$ & 0 & 2160 & 0 \\
\hline 12 & $720+1440(\mathrm{~V} 3+\mathrm{V} 7)$ & 350 (V5) & 2160 & 350 \\
\hline
\end{tabular}

A fonte utilizada de glifosato foi o Roundup Original (nome comercial), cuja formulação corresponde a seguinte composição: Sal de Isopropilamina de $\mathrm{N}$ - (fosfonometil) glicina $480 \mathrm{~g} \mathrm{~L}^{-}$ $1(48,0 \% \mathrm{~m} / \mathrm{v})$, equivalente ácido de $\mathrm{N}$ (fosfonometil) glicina (glifosato) $360 \mathrm{~g} \mathrm{~L}^{-1}(36,0 \%$ $\mathrm{m} / \mathrm{v})$, ingredientes inertes de $684 \mathrm{~g} \mathrm{~L}^{-1}(68,4 \% \mathrm{~m} / \mathrm{v})$. A aplicação de $\mathrm{Mn}$ foi em 07/12, no estádio V5. A fonte utilizada apresentava as seguintes características: Produto líquido a base de sulfato de Mn quelatizado com EDTA, contendo $20 \%$ de $\mathrm{Mn}$ e densidade de $1,65 \mathrm{~g} \mathrm{~L}^{-1}$.
O controle de plantas daninhas foi realizado com aplicação em área total com os herbicidas à base de fenoxaprop-p-ethyl $(77 \mathrm{~g}$ i.a. $\left.\mathrm{ha}^{-1}\right)+$ óleo mineral parafinico $(0,5 \%$ do volume da calda), aplicados no dia 23/11/2012 e lactofem $\left(120\right.$ g i.a. ha $\left.{ }^{-1}\right)+$ bentazona (600 g i.a. ha ${ }^{-1}$ ), aplicados no dia 10/12/2012. O manejo de pragas foi realizado com a aplicação de três inseticidas: cipermetrina (50 g i.a. ha $\left.{ }^{-1}\right)+$ metomil $(107,5$ g i.a. $\mathrm{ha}^{-1}$ ), no dia 08/01, imidacloprid + beta-ciflutrina $\left(156,25+7,03\right.$ g i.a. ha ${ }^{-1}$, respectivamente $)+$ metomil $\left(107,5\right.$ g i.a. $\left.h^{-1}\right)$, no dia 20/01/2013, e 
imidacloprid + beta-ciflutrina $(156,25+7,03$ g i.a. ha ${ }^{1}$, respectivamente) + metomil $\left(107,5 \mathrm{~g}\right.$ i.a. ha $\left.{ }^{-1}\right)$, no dia 13/02/2013. O manejo de doenças foi realizado preventivamente com três aplicações de fungicidas: piraclostrobina + epoxiconazol $\left(13,25+12,5\right.$ g i.a. ha $^{-1}$, respectivamente), nos dias 08/01, 28/01 e 13/02.

No estádio R2 (florescimento pleno) da cultura (06/01) foi coletado na área útil de cada parcela, trinta folhas totalmente desenvolvida, sendo esta a 3a folha do ápice na haste principal, conforme metodologia descrita por Raij et al. (2001). No total, foram coletadas de maneira aleatória trinta folhas em cada parcela, as quais foram levadas ao laboratório, lavadas com água corrente e detergente a $1 \%$ e posteriormente em água destilada e deionizada. 0 material foi acondicionado em sacos de papel e colocado para secar em estufa de circulação e renovação de ar forçado a $60-70{ }^{\circ} \mathrm{C}$ até massa constante. Após secagem, as folhas foram moídas, em moinho tipo Willey, para determinação das concentrações de $\mathrm{N}$, $\mathrm{P}, \mathrm{K}, \mathrm{Ca}, \mathrm{Mg}, \mathrm{S}, \mathrm{Fe}, \mathrm{Mn}$ e Zn foliar, de acordo com a metodologia de Malavolta et al. (1997).

No estádio R8 (12/03) foi realizada a coleta de material para avaliação das características agronômicas e produtividade de grãos. Para estas avaliações foram coletadas amostras de dez plantas representativas, seguidas em uma das três linhas centrais de cada parcela. Essas plantas, após a identificação, foram levadas ao laboratório para as avaliações de altura de plantas, altura de inserção da primeira vagem, números de vagens e de grãos por planta.

Para estimar a produtividade de grãos foram colhidas todas as plantas contidas nas três linhas de três metros de comprimento. Estas plantas, após serem secas ao sol, foram trilhadas mecanicamente por uma trilhadora estacionária e os grãos obtidos foram abanadas para retirar as impurezas e acondicionados em sacos de papel. Com auxílio de uma balança, foi obtida a massa dos grãos de cada amostra, sendo os dados transformados em $\mathrm{kg} \mathrm{ha}^{-1}$. Logo após, foi retirado uma amostra de grãos de cada saquinho para determinação da umidade (método da estufa - 105 $\pm 3^{\circ} \mathrm{C} / 24$ horas), para posterior correção da massa da produção obtida à $13 \%$ de umidade (base úmida).

Simultaneamente à avaliação de produtividade, foi realizada a determinação da massa de cem grãos. Para isso, em cada amostra foi contado à respectiva quantidade de grãos, pesados em uma balança de precisão $(0,01 \mathrm{~g})$. O valor obtido também foi corrigido para $13 \%$ de umidade (base úmida).

Os dados foram submetidos à análise de variância (Teste $F$ ) e as médias dos tratamentos foram comparadas pelo teste de Tukey a $5 \%$ de probabilidade, por meio do programa computacional SISVAR (FERREIRA, 2011).

\section{RESULTADOS E DISCUSSÃO}

As concentrações de $\mathrm{N}, \mathrm{P}, \mathrm{K}, \mathrm{Ca}, \mathrm{Mg}, \mathrm{S}, \mathrm{Fe}$, $M n$ e $Z n$ não foram influenciadas pelas doses de glifosato e também pela aplicação de $\mathrm{Mn}$ foliar (Tabelas 2 e 3). Vale ressaltar que as concentrações de $\mathrm{N}, \mathrm{P}, \mathrm{K}, \mathrm{Ca}, \mathrm{Mg}$, S e Fe estavam dentro da faixa preconizada por Ambrosano et al. (1997) como ideal, que variam de 40 a $54 ; 2,5$ a 5,0; 17 a $25 ; 4$ a 20; 3,0 a 10,0; 2,1 a $4,0 \mathrm{~g} \mathrm{~kg}^{-1}$ de M.S. e 50 a $350 \mathrm{mg}$ $\mathrm{kg}^{-1}$ de M.S., respectivamente. Para as concentrações foliares de $\mathrm{Mn}$ e $\mathrm{Zn}$, os valores verificados estavam acima da faixa preconizada como ideal por Ambrosano et al. (1997), que varia de 20 a 100 e 20 a 50 mg kg ${ }^{-1}$ de M.S., respectivamente. 
Tabela 2. Concentração foliar de $\mathrm{N}, \mathrm{P}, \mathrm{K}, \mathrm{Ca}, \mathrm{Mg}$ e $\mathrm{S}\left(\mathrm{g} \mathrm{kg}^{-1}\right)$, em função de doses de aplicação de glifosato e de Mn via foliar na cultura da soja. Selvíria - MS, Brasil, 2013

\begin{tabular}{|c|c|c|c|c|c|c|}
\hline \multirow{2}{*}{ Tratamentos } & $\mathrm{N}$ & $P$ & K & $\mathrm{Ca}$ & $\mathrm{Mg}$ & $\mathrm{S}$ \\
\hline & \multicolumn{6}{|c|}{$\left(\mathrm{g} \mathrm{kg}^{-1}\right)$} \\
\hline \multicolumn{7}{|c|}{ Doses Glifosato (g i.a. ha ${ }^{-1}$ ) } \\
\hline 0 & 45,9 & 4,4 & 19,9 & 6,4 & 3,6 & 2,7 \\
\hline 720 (V3) & 46,7 & 4,1 & 18,3 & 6,3 & 3,4 & 2,8 \\
\hline $720+720(V 3+V 7)$ & 47,1 & 4,2 & 18,3 & 6,6 & 3,7 & 2,9 \\
\hline 1440 (V3) & 49,5 & 4,2 & 18,3 & 6,3 & 3,3 & 2,6 \\
\hline 1440 (V7) & 50,2 & 4,1 & 17,8 & 6,1 & 3,3 & 2,7 \\
\hline $720+1440(\mathrm{~V} 3+\mathrm{V} 7)$ & 42,8 & 4,2 & 18,4 & 6,5 & 3,4 & 2,6 \\
\hline \multicolumn{7}{|c|}{ Doses $\mathrm{Mn}\left(\mathrm{g} \mathrm{ha}^{-1}\right)$} \\
\hline 0 & 46,5 & 4,1 & 18,4 & 6,4 & 3,5 & 2,7 \\
\hline 350 (V5) & 47,5 & 4,3 & 18,2 & 6,4 & 3,4 & 2,8 \\
\hline \multicolumn{7}{|c|}{ F calculado (Fc) } \\
\hline Glifosato (G) & $1,59^{\text {ns }}$ & $1,10^{\mathrm{ns}}$ & $0,43^{\text {ns }}$ & $0,44^{\mathrm{ns}}$ & $0,75^{\mathrm{ns}}$ & $0,46^{\mathrm{ns}}$ \\
\hline $\mathrm{Mn}$ & $0,38^{\text {ns }}$ & $3,32^{\mathrm{ns}}$ & $0,14^{\text {ns }}$ & $0,07^{\text {ns }}$ & $0,02^{\text {ns }}$ & $0,73^{\mathrm{ns}}$ \\
\hline GxMn & $0,06^{\mathrm{ns}}$ & $0,31^{\mathrm{ns}}$ & $0,07^{\text {ns }}$ & $0,66^{\mathrm{ns}}$ & $0,54^{\text {ns }}$ & $0,52^{\mathrm{ns}}$ \\
\hline Média & 47,0 & 4,2 & 18,3 & 6,4 & 3,5 & 2,7 \\
\hline C.V.\% & 12,53 & 7,03 & 8,34 & 12,97 & 13,44 & 15,26 \\
\hline
\end{tabular}

* Significativo $5 \%$ de probabilidade. ns - não significativo

Tabela 3. Concentração foliar de $\mathrm{Fe}, \mathrm{Mn}$ e $\mathrm{Zn}\left(\mathrm{mg} \mathrm{kg}^{-1}\right)$, em função de doses de aplicação de glifosato e de $\mathrm{Mn}$ via foliar na cultura da soja. Selvíria - MS, Brasil, 2013

\begin{tabular}{|c|c|c|c|}
\hline \multirow{2}{*}{ Tratamentos } & $\mathrm{Fe}$ & $\mathrm{Mn}$ & $\mathrm{Zn}$ \\
\hline & \multicolumn{3}{|c|}{$\left(\mathrm{mg} \mathrm{kg}^{-1}\right)$} \\
\hline \multicolumn{4}{|c|}{ Doses Glifosato (g i.a. ha ${ }^{-1}$ ) } \\
\hline 0 & 166,2 & 176,5 & 61,2 \\
\hline 720 (V3) & 161,2 & 188,7 & 68,7 \\
\hline $720+720(\mathrm{~V} 3+\mathrm{V} 7)$ & 161,2 & 173,7 & 70,0 \\
\hline 1440 (V3) & 153,7 & 162,5 & 55,0 \\
\hline 1440 (V7) & 161,2 & 161,2 & 56,2 \\
\hline $720+1440(V 3+V 7)$ & 158,7 & 175,0 & 63,7 \\
\hline \multicolumn{4}{|c|}{ Doses $\mathrm{Mn}\left(\mathrm{g} \mathrm{ha}^{-1}\right)$} \\
\hline 0 & 160,4 & 167,0 & 62,5 \\
\hline 350 (V5) & 160,4 & 175,8 & 62,5 \\
\hline \multicolumn{4}{|c|}{ F calculado $(\mathrm{Fc})$} \\
\hline Glifosato (G) & $0,43^{\mathrm{ns}}$ & $0,92^{\text {ns }}$ & $2,39^{\text {ns }}$ \\
\hline $\mathrm{Mn}$ & $0,99^{\text {ns }}$ & $1,02^{\mathrm{ns}}$ & $0,99^{\text {ns }}$ \\
\hline GxMn & $1,54^{\mathrm{ns}}$ & $0,89^{\text {ns }}$ & $1,08^{\mathrm{ns}}$ \\
\hline Média & 160,4 & 171,4 & 62,5 \\
\hline C.V.\% & 10,92 & 17,46 & 18,19 \\
\hline
\end{tabular}

* Significativo $5 \%$ de probabilidade.

ns - não significativo

$\mathrm{O} \mathrm{pH}$ do solo do experimento encontravase baixo $(5,0)$, e possivelmente proporcionou maior disponibilidade de $\mathrm{Mn}$ e $\mathrm{Zn}$ às plantas, em função da maior solubilidade dos compostos formados por esses nutrientes, o que se reflete na elevada concentração foliar desses micronutrientes, em função da maior disponibilidade às plantas dos micronutrientes catiônicos em pH baixo (solo ácido), conforme relatado por Malavolta (2006). O teor de Fe não foi influenciado pela aplicação de 
Mn (Tabela 3), não houve efeito antagônico na absorção de $\mathrm{Fe}$, pois o $\mathrm{Mn}$ foi aplicado via foliar.

Diferentemente, Zobiole et al. (2011) e

Gonçalves et al. (2014) relataram o desenvolvimento das plantas sendo afetado diretamente pela dosagem e tipo do herbicida aplicado, sendo verificado nas testemunhas o maior acúmulo de nutrientes, o que segundo Johal e Huber (2009) está diretamente correlacionado com o decréscimo no conteúdo de clorofila, a eficiência fisiológica da planta, a predisposição a doenças e a modificação da microflora do solo, devido ao aumento da dosagem e à utilização do herbicida. De acordo com Cavalieri et al. (2012), o glifosato interfere de forma negativa na eficiência de absorção e, consequentemente, de acúmulo de nutrientes, mesmo para as cultivares RR. Santos et al. (2007) indicaram que não se deve aplicar a formulação de glifosato em doses elevadas, visto que o herbicida é capaz de alterar o teor de nutrientes nas folhas da cultura, corroborando com Serra et al. (2011), que verificaram que a aplicação de doses de glifosato $(0 ; 0,648 ; 1,296 ; 1,944$ e 2,592 kg i.a. ha ${ }^{-1}$ ) interferiu de forma negativa na eficiência de absorção de $\mathrm{N}$ e $\mathrm{Fe}$, uso de $\mathrm{N}$, Fe e $\mathrm{Cu}$ na planta e nas concentrações totais de $\mathrm{N}, \mathrm{Mn}, \mathrm{Zn}$, $\mathrm{Cu}$ e $\mathrm{Fe}$, entretanto, os resultados obtidos no presente trabalho não comprovam tais afirmações, em função da ausência de influência do glifosato nas concentrações de nutrientes no tecido foliar.

Os resultados obtidos para concentração de $\mathrm{Mn}$ foliar indicam que a aplicação de glifosato na cultura da soja não afetou a absorção desse nutriente, corroborando com os dados apresentados em outros trabalhos (BOTT et al., 2008; CORREIA; DURIGAN, 2009). Resultados semelhantes foram obtidos por Rosolem et al. (2010), estudando os efeitos do glifosato na cinética de absorção, acumulação e distribuição do Mn em soja, também não verificaram influência na concentração de $\mathrm{Mn}$ no tecido foliar em função da aplicação de glifosato. De maneira semelhante, Basso et al. (2011), aplicando $720 \mathrm{~g}$ i.a. de glifosato no estádio V5 da cultura da soja também não constataram influência do herbicida na concentração de $\mathrm{Mn}$ nas folhas.
As doses de glifosato aplicadas em diferentes estádios fenológicos, assim como a aplicação de $\mathrm{Mn}$ via foliar não influenciaram a altura de plantas, número de vagens por planta e massa de 100 grãos (Tabela 4). Esses resultados concordam com os relatados por Correia e Durigan (2009), Stefanello et al. (2011) e Fenner et al. (2012), que não observaram diferença entre os tratamentos com aplicação de glifosato e adubação foliar de $\mathrm{Mn}$ nos componentes produtivos da cultura da soja, justificada pelo elevado teor de $\mathrm{Mn}$ do solo para os locais de condução do experimento. Portanto, em solos com teores de $\mathrm{Mn}$ adequado, não é necessária suplementação foliar do nutriente em soja geneticamente modificada e tolerante ao glifosato (BASSO et al., 2011), portanto, como o teor de $\mathrm{Mn}$ inicial do solo estava médio, de acordo com Raij et al. (2001), isto explica porque não houve reposta a adubação foliar com $\mathrm{Mn}$. Alguns fatores podem causar redução na altura da planta, como, a menor quantidade de palha no início de plantio, com prejuízos ao estabelecimento da cultura da soja, liberação de substâncias inibidoras de crescimento e de desenvolvimento de soja durante a decomposição da palhada das culturas antecessoras (SANTOS et al., 2007), entretanto tais interferências não foram verificadas no presente trabalho. $A$ interação entre doses de glifosato e aplicação de $M n$ foi significativa para a altura de inserção da primeira vagem (Tabela 5). Na dose de glifosato $720+1440 \mathrm{~g}$ i.a. ha ${ }^{-1}$ aplicados em V3 e V7 aliado à aplicação de $\mathrm{Mn}$ foliar, a altura de inserção foi inferior comparativamente a não aplicação de $\mathrm{Mn}$. Entretanto, a interação entre doses de glifosato e aplicação de $\mathrm{Mn}$ foi significativa para o número de grãos por vagem, onde na dose de glifosato 720+1440 g i.a. ha ${ }^{-1}$ aplicados em V3 e V7 aliado à aplicação de $\mathrm{Mn}$ foliar, o número de grãos foi maior comparativamente a não aplicação de $\mathrm{Mn}$ (Tabela 6), ou seja, na dose de 720+1440 g i.a. ha ${ }^{-1}$ aplicados em V3 e V7, o Mn aplicado via foliar reduziu a altura de inserção da primeira vagem, entretanto essa redução não afetou o número de grãos por vagem, que foi beneficiado com a aplicação de $\mathrm{Mn}$ (Tabelas 5 e 6). 
Tabela 4. Alturas de plantas e de inserção da 1ạ vagem, números de vagens por planta e de grãos por vagem, massa de 100 grãos e produtividade de grãos de soja em função de doses de aplicação de glifosato e de Mn via foliar na cultura da soja. Selvíria - MS, Brasil, 2013

\begin{tabular}{|c|c|c|c|c|c|c|}
\hline \multirow[t]{2}{*}{ Tratamentos } & $\begin{array}{l}\text { Altura } \\
\text { de } \\
\text { Planta }\end{array}$ & $\begin{array}{l}\text { Inserção } \\
\text { primeira } \\
\text { vagem }\end{array}$ & $\begin{array}{c}\text { № de vagens } \\
\text { por planta }\end{array}$ & $\begin{array}{l}\text { № de grãos } \\
\text { por vagem }\end{array}$ & $\begin{array}{l}\text { Massa } \\
\text { de } 100 \\
\text { grãos }\end{array}$ & $\begin{array}{c}\text { Produtividade } \\
\text { de grãos }\end{array}$ \\
\hline & \multicolumn{2}{|c|}{$(\mathrm{cm})$} & & & (g) & $\left(\mathrm{kg} \mathrm{ha}^{-1}\right)$ \\
\hline \multicolumn{7}{|c|}{ Doses de Glifosato (g i.a. ha ${ }^{-1}$ ) } \\
\hline 0 & 85,4 & 16,6 & 37,8 & 1,7 & 14,9 & $2682 a b$ \\
\hline 720 (V3) & 85,7 & 16,8 & 34,8 & 1,6 & 14,3 & $2686 a b$ \\
\hline $720+720(V 3+V 7)$ & 83,1 & 16,8 & 41,7 & 1,8 & 14,1 & $2530 a b$ \\
\hline $1440(\mathrm{~V} 3)$ & 83,5 & 17,1 & 42,9 & 1,9 & 13,8 & 2885 a \\
\hline 1440 (V7) & 84,5 & 17,4 & 41,2 & 1,8 & 14,8 & $2847 a$ \\
\hline $720+1440$ (V3+V7) & 80,8 & 16,7 & 31,9 & 1,6 & 14,3 & $2257 \mathrm{~b}$ \\
\hline \multicolumn{7}{|c|}{ Doses $\mathrm{Mn}\left(\mathrm{g} \mathrm{ha}^{-1}\right)$} \\
\hline 0 & 84,8 & 17,0 & 38,5 & 1,8 & 14,4 & 2596 \\
\hline 350 (V5) & 82,9 & 16,7 & 38,3 & 1,9 & 14,3 & 2699 \\
\hline \multicolumn{7}{|c|}{ F calculado (Fc) } \\
\hline Glifosato (G) & $0,58^{\text {ns }}$ & $0,13^{\mathrm{ns}}$ & $2,27^{\text {ns }}$ & $3,18^{*}$ & $1,00^{\text {ns }}$ & $3,72 *$ \\
\hline $\mathrm{Mn}$ & $0,94^{\mathrm{ns}}$ & $0,24^{\mathrm{ns}}$ & $0,00^{\text {ns }}$ & $1,53^{\mathrm{ns}}$ & $0,15^{\mathrm{ns}}$ & $1,13^{\mathrm{ns}}$ \\
\hline GxMn & $1,03^{\mathrm{ns}}$ & $2,59 *$ & $0,74^{\mathrm{ns}}$ & $2,15^{*}$ & $0,27^{\mathrm{ns}}$ & $0,89^{\text {ns }}$ \\
\hline Média & 83,8 & 16,9 & 38,3 & 1,9 & 14,4 & 2648 \\
\hline C.V.\% & 7,91 & 13,52 & 21,32 & 8,43 & 8,30 & 12,74 \\
\hline
\end{tabular}

* Significativo $5 \%$ de probabilidade.

ns - não significativo.

Médias seguidas pela mesma letra maiúscula na coluna e minúscula na linha não diferem entre si, pelo teste de Tukey à $5 \%$ de probabilidade.

Tabela 5. Desdobramento da interação entre doses de glifosato e aplicação de $\mathrm{Mn}$ via foliar na altura de inserção da 1a vagem da cultura da soja. Selvíria-MS, Brasil, 2013

\begin{tabular}{ccccccc}
\hline \multirow{2}{*}{$\begin{array}{c}\text { Doses } \mathrm{Mn} \\
\left(\mathrm{g} \mathrm{ha}^{-1}\right)\end{array}$} & 0 & $720(\mathrm{~V} 3)$ & $\begin{array}{c}720+720 \\
\text { (V3+V7) }\end{array}$ & $1440(\mathrm{~V} 3)$ & $1440(\mathrm{V7})$ & $\begin{array}{c}720+1440 \\
\text { (V3+V7) }\end{array}$ \\
\cline { 2 - 6 } & $16,6 \mathrm{Aa}$ & $17,2 \mathrm{Aa}$ & $\begin{array}{c}17,0 \mathrm{Aa} \\
16\end{array}$ & $16,3 \mathrm{Aa}$ & $16,1 \mathrm{Aa}$ & $19,1 \mathrm{Aa}$ \\
$350(\mathrm{~V} 5)$ & $16,6 \mathrm{Aa}$ & $17,3 \mathrm{Aa}$ & $17,5 \mathrm{Aa}$ & $17,9 \mathrm{Aa}$ & $18.7 \mathrm{Aa}$ & $14,2 \mathrm{Ba}$ \\
\hline
\end{tabular}

Médias seguidas pela mesma letra maiúscula na coluna e minúscula na linha não diferem entre si, pelo teste de Tukey à $5 \%$ de probabilidade.

Tabela 6. Desdobramento da interação entre doses de glifosato e aplicação de $\mathrm{Mn}$ via foliar no número de grãos por vagem da cultura da soja. Selvíria - MS, Brasil, 2013

\begin{tabular}{|c|c|c|c|c|c|c|}
\hline \multirow{2}{*}{$\begin{array}{c}\text { Doses Mn (g } \\
\left.\mathrm{ha}^{-1}\right)\end{array}$} & \multicolumn{6}{|c|}{ Doses de Glifosato (g i.a. ha $^{-1}$ ) } \\
\hline & 0 & 720 (V3) & $\begin{array}{l}720+720 \\
(\mathrm{~V} 3+\mathrm{V} 7)\end{array}$ & 1440 (V3) & 1440 (V7) & $\begin{array}{c}720+1440 \\
(\mathrm{~V} 3+\mathrm{V} 7)\end{array}$ \\
\hline 0 & $1,7 \mathrm{Aa}$ & $1,8 \mathrm{Aa}$ & $2,0 \mathrm{Aa}$ & $1,7 \mathrm{Aa}$ & 1,9Aa & $1,7 \mathrm{Ba}$ \\
\hline 350 (V5) & $1,7 \mathrm{Ab}$ & $1,5 \mathrm{Ab}$ & $1,8 \mathrm{Ab}$ & $1,8 \mathrm{Ab}$ & $1,8 \mathrm{Ab}$ & $2,0 \mathrm{Aa}$ \\
\hline
\end{tabular}

Médias seguidas pela mesma letra maiúscula na coluna e minúscula na linha não diferem entre si, pelo teste de Tukey à $5 \%$ de probabilidade. 
A produtividade de grãos de soja foi influenciada pelas doses de glifosato, com maior produtividade nos tratamentos com a dose aplicada de $1440 \mathrm{~g}$ i.a. ha ${ }^{-1}$ de glifosato no estádio V3 e 1440 g i.a. ha ${ }^{-1}$ de glifosato no estádio V7 (2885 e $2847 \mathrm{~kg} \mathrm{ha}{ }^{-1}$, respectivamente), comparativamente a aplicação na dose de $720+1440$ g i.a. ha ${ }^{-1}$ de glifosato nos estádios V3 e V7 (2257 kg ha $\left.{ }^{-1}\right)$, não diferindo das doses zero (testemunha), $720 \mathrm{~g}$ i.a. ha ${ }^{-1}$ aplicado no estádio V3 e $720+720$ g i.a. ha ${ }^{-1}$ de glifosato aplicados no estádio V3 e V7 (Tabela 4), respectivamente, corroborando com Albrecht et al. (2011), que preconizam que elevadas doses de glifosato podem diminuir a produtividade de grãos de soja. Vale destacar que houve um incremento médio $184 \mathrm{~kg}$ ha $^{-1}$ de grãos, com os dois tratamentos supracitados que se destacaram, em relação a testemunha que não recebeu a aplicação de glifosato.

Segundo Zobiole et al. (2010), há evidências que sugerem que a produtividade da soja resistente ao glifosato seja menor do que a das sojas convencionais. Muitos agricultores têm observado que tais produtividades, mesmo sob condições ótimas, não são tão elevadas, como esperado. Ainda segundo os autores, as aplicações de glifosato podem retardar o metabolismo do $\mathrm{Mn}$ na planta, bem como ter um efeito adverso nas populações de microrganismos do solo que são responsáveis pela redução do $\mathrm{Mn}$ em forma disponível para a planta, e que a adição de $\mathrm{Mn}$ suplementar, no período adequado, pode corrigir os sintomas de deficiência e resultar em maiores produtividades de soja, contudo, este resultado não foi observado nesta pesquisa.

Diferentemente, Stefanello et al. (2011), aplicando $1200 \mathrm{~g}$ i.a. de glifosato em combinações de estádio vegetativo (V2 e V2+V4), não verificaram influência do glifosato na produtividade de grão de soja transgênica, corroborando com Correia e Durigan (2009). De maneira semelhante, Basso et al. (2011), aplicando $720 \mathrm{~g}$ i.a. de glifosato no estádio V5 também não verificaram influência do glifosato na produtividade de grão de soja transgênica e de acordo com os autores, a soja que foi geneticamente modificada pela adição de um gene que codifica a enzima EPSPS torna-se tolerante à ação do glifosato e continua produzindo compostos essenciais ao seu desenvolvimento e seu crescimento, não sendo afetada pelos efeitos do herbicida, além disso, a clorose que aparece na soja após aplicação do glifosato é mais acentuada quanto mais precoce for a aplicação e se intensifica à medida que ocorre um aumento na dose. Os sintomas de injúria gerados nas plantas dependem das doses de glifosato utilizadas, sendo que as maiores concentrações de glifosato levam a maiores formações do composto secundário AMPA, que pode causar redução na produtividade, como verificado no presente trabalho (ZABLOTOWCZ; REDDY, 2007; SERRA et al., 2011).

De acordo com Serra et al. (2011), o dano nas plantas de soja é provocado pela proporção de sal que está presente nas formulações comerciais de glifosato e não pelo produto glifosato. Nesse contexto, Santos et al. (2007) observaram efeito variável do glifosato no desenvolvimento da soja $R R$, em função da formulação com que o produto comercial é produzido, levantando a questão de que a aplicação de $720+1440$ g i.a. de glifosato aplicados em V3 e V7 pode ter sido muito elevada a ponto de ter ocasionado certo de grau de fitotoxidez, influenciando negativamente a produtividade de grão de soja.

\section{CONCLUSÕES}

A aplicação foliar de $\mathrm{Mn}$ e de glifosato não influencia as concentrações foliar de $\mathrm{N}, \mathrm{P}, \mathrm{K}, \mathrm{Ca}$, $\mathrm{Mg}, \mathrm{S}, \mathrm{Fe}, \mathrm{Mn}$ e $\mathrm{Zn}$ da cultura da soja.

O glifosato nas doses de $720+1440$ g i.a. $\mathrm{ha}^{-1}$, aplicado nos estádios V3 e V7, associado a adubação foliar com $350 \mathrm{~g} \mathrm{ha}^{-1}$ de $\mathrm{Mn}$ no estádio V5, reduz a altura de inserção da primeira vagem, porém aumenta o número de grão por vagem.

A produtividade de grãos de soja é reduzida com a aplicação de glifosato na dose de 720+1440 g i.a. ha ${ }^{-1}$, nos estádios V3 e V7, independentemente da aplicação foliar com Mn.

\section{REFERÊNCIAS}

ALBRECHT, L.P.; BARBOSA, A.P.; SILVA, A.F.M.; MENDES, M.A.; MARASCHI-SILVA, L.M.; ALBRECHT, A.J.P. Desempenho da soja roundup ready sob aplicação de glyphosate em diferentes estádios. Planta Daninha, v.29, n.3, p.585-590, 2011. https://doi.org/10.1590/S0100$\underline{83582011000300012}$ 
AMBROSANO, E.J.; TANAKA, R.T.; MASCARENHAS, H.A.A. Leguminosas e oleaginosas. In: RAIJ, B. VAN; CANTARELLA, H.; QUAGGIO, J.A.; FURLANI, A.M.C. Recomendações de calagem e adubação para o Estado de São Paulo. Campinas: Instituto Agronômico de Campinas, 285p. (Boletim técnico, 100), 1997.

BASSO, C.J.; SANTI, A.L. LAMEGO, F.P.; GIROTTO, E. Aplicação foliar de manganês em soja transgênica tolerante ao glyphosate. Ciência Rural, v.41, n.10, p.1726-1731, 2011. https://doi.org/10.1590/S0103$\underline{84782011001000008}$

BIANCO, S.; CARVALHO, L.B.; BIANCO, M.S.; PITELLI, R.A. Acúmulo de massa seca e macronutrientes por plantas de Glycine max e Solanum americanum. Planta Daninha, v.30, n.1, p.87-95, 2012. https://doi.org/10.1590/S0100$\underline{83582012000100010}$

BOTT, S.; TESFAMARIAM, T.; CANDAN, H.; CAKMAK, I.; RÖMHELD, V.; NEUMANN, G. Glyphosateinduced impairment of plant growth and micronutriente status in glyphosate-resistant soybean (Glycine max L.). Plant and Soil, v.312, n., p.185-194, 2008.

CARVALHO, E.R.; OLIVEIRA, J.A.; REIS, L.V.; FERREIRA, T.F. Mn foliar sobre a qualidade sanitária e lignina de sementes de soja convencional e resistente ao glifosato. Revista Ciência Agronômica v.46, n.1, p.135-143, 2015. https://doi.org/10.1590/S1806-

$\underline{66902015000100016}$

CAVALIERI, S.D.; VELINI, E.D.; SILVA, F.M.L.; SÃO JOSÉ, A.R.; ANDRADE, G.J.M. Acúmulo de nutrientes e matéria seca na parte aérea de dois cultivares de soja RR sob efeito de formulações de glyphosate. Planta Daninha v.30, n.2, p.349-358, $2012 . \quad \quad$ https://doi.org/10.1590/S010083582012000200014

COMPANHIA NACIONAL DE ABASTECIMENTOCONAB. Avaliação da safra agrícola 2015/2016: primeiro levantamento - outubro/2015. Brasília: CONAB, 2015. Disponível em: <http://www.conab.gov.br/OlalaCMS/uploads/arq uivos/15_10_09_17_45_57_boletim_graos_outubr o_2015_novo.pdf> Acesso em: 12 out. 2015.

CORREIA, N.Z.; DURIGAN, J.C. Glyphosate e adubação foliar com manganês na cultura da soja transgênica. Planta Daninha v.27, n. 4, p.721-727, 2009. https://doi.org/10.1590/S0100$\underline{83582009000400010}$

EMBRAPA. Centro Nacional de Pesquisa de Solos. Sistema brasileiro de classificação de solos. 3. ed. Brasília, DF: Embrapa, 2013. 353 p.

EMBRAPA. Tecnologia de produção de soja Região Central do Brasil - 2006. Londrina: Embrapa Soja, Embrapa Cerrados, Embrapa Agropecuária Oeste, 225 p. (Embrapa Soja. Sistema de Produção, 9), 2006.

FENNER, A.; FENNER, W.; OKUMURA, R.S.; MARIANO, D.C.; DALLACORT, R.; BATISTTI, M.; PICCININ, G.G. Aplicação foliar de manganês em soja geneticamente modificada submetida a doses de glyphosate. Revista Brasileira de Herbicidas, v.11, n.3, p.322-331, 2012. https://doi.org/10.7824/rbh.v11i3.185

FERREIRA, D.F. Sisvar: a computer statistical analysis system. Ciência e Agrotecnologia, v.35, n.6, p.1039-1042, 2011. https://doi.org/10.1590/S1413-

$\underline{70542011000600001}$

GONÇALVES, J.M.; SOUZA, E.R.B.; FERNANDES, E.P.; LEANDRO, W.M.; TAVARES, C.J. Eficiência nutricional da soja RR na ausência do glifosato. Científica, v.42, n.2, p.157-163, 2014. https://doi.org/10.15361/1984-

5529.2014v42n2p157-163

HUBER, D.M. What about glyphosate-induced manganese deficiency? Fluid Journal v.15, n., p.2022, 2007.

IGNÁCIO, V.L.; NAVA, I.A.; MALAVASI, M.M.; GRIS, E.P. Influence of foliar fertilization with manganese on germination, vigor and storage time of $R R$ soybean seeds. Revista Ceres, v.62, n.5, p.446-452, 2015. https://doi.org/10.1590/0034$\underline{737 \times 201562050004}$ 
JOHAL, G.S.; HUBER, D.M. Glyphosate effects on diseases of plants. European Journal of Agronomy v.31, n.3, p. 144-152, 2009. https://doi.org/10.1016/j.eja.2009.04.004

MALAVOLTA, E. Manual de nutrição mineral de plantas. São Paulo: Livroceres, 638 p, 2006.

MALAVOLTA, E.; VITTI, G.C.; OLIVEIRA, S.A. Avaliação do estado nutricional das plantas: princípios e aplicações. 2. ed. Piracicaba: Potafós, 319 p, 1997.

RAIJ, B. VAN; ANDRADE, J.C.; CANTARELLA, H.; QUAGGIO, J.A. Análise química para avaliação da fertilidade de solos tropicais. Campinas: IAC, 285 p, 2001.

ROSOLEM, C.A.; ANDRADE, G.J.M.; LISBOA, I.P.; ZOCA, S.M. Manganese uptake and redistribution in soybean as affected by glyphosate. Revista Brasileira de Ciência do Solo v.34, n.6, p.19151922, 2010. https://doi.org/10.1590/S0100$\underline{06832010000600016}$

SANTOS, J.B.; FERREIRA, E.A.; REIS, M.R.; SILVA, A.A.; FIALHO, C.M.T.; FREITAS, M.A.M. Avaliação de formulações de Glyphosate sobre soja Roundup Ready. Planta Daninha, v.25, n.1, p. 165-171, 2007. https://doi.org/10.1590/s0100-

$\underline{83582007000100018}$

SERRA, A.P.; MARCHETTI, M.E.; CANDIDO, A.C.S.; DIAS, A.C.R.; CHRISTOFFOLETI, P.J. Influência do glifosato na eficiência nutricional do nitrogênio, manganês, ferro, cobre e zinco em soja resistente ao glifosato. Ciência Rural, v..41, n.1, p. 77-84, $2011 . \quad$ https://doi.org/10.1590/S0103$\underline{84782011000100013}$

STEFANELLO, F.F.; MARCHETTI, E.M.; SILVA, F.E.; STEFANELLO, J.; DORETO, S.B.R.; NOVELINO, O.J. Efeito de glyphosate e manganês na nutrição e produtividade da soja transgênica. Semina Ciências Agrárias v.32, n.3, p. 1007-1014, 2011. https://doi.org/10.5433/1679-

$\underline{0359.2011 v 32 n 3 p 1007}$
YAMADA, T.; CASTRO, P.R.C. Efeito do glifosato nas plantas: implicações fisiológicas e agronômicas. Encarte técnico. Informações Agronômicas, n.119, 2007.

ZABLOTOWICZ, R.M.; REDDY, K.N. Nitrogenase activity, nitrogen content, and yield responses to glyphosate in glyphosate-resistant soybean. Crop Protection, v.26, n.3, p. 370-376, 2007. https://doi.org/10.1016/j.cropro.2005.05.013

ZOBIOLE, L.H.S.; KREMER, R.J.; OLIVEIRA JUNIOR, R.S.; CONSTANTIN, J. Glyphosate affects chlorophyll, nodulation and nutrient accumulation of "second generation" glyphosate-resistant soybean (Glycine max L.). Pesticide Biochemistry and Physiology, v.99, n.1, p.53-60, 2011. https://doi.org/10.1016/j.pestbp.2010.10.005

ZOBIOLE, L.H.S.; OLIVEIRA JUNIOR, R.S.; VISENTAINER, J.V.; KREMER, R.J.; BELLALOUI, N.; YAMADA, T. Glyphosate affects seed composition in glyphosate-resistant soybean. Journal of Agricultural and a Food Chemistry, v. 58, n.7, p. 4517-4522, 2010.

Recebido para publicação em 02/05/2018

Revisado em 05/07/2018

Aceito em 28/12/2018 